\title{
Massive cerebral air embolism in a preterm with fetal alcohol syndrome
}

\author{
Tai-H eng Chen ${ }^{1,2}$, Yuh-Jyh Jong ${ }^{1,2}$, Rei-Cheng Yang ${ }^{1}$, San-N an Yang ${ }^{2,3}$ \\ ${ }^{1}$ Division of Pediatric Neurology, ${ }^{2}$ Graduate Institute of Medicine, College of Medicine, ${ }^{3}$ Division of Neonatology, Department of \\ Pediatrics, Kaohsiung Medical University Hospital, Kaobsiung, Taiwan
}

A mother with history of alcoholism during pregnancy delivered a baby boy weighing 1660 gms at $33^{\text {th }}$ weeks of gestation. The baby had features of fetal alcoholic syndrome (FAS) in the form of facial dysmorphic features, bilateral optic atrophy, and sensorineural hearing loss. The baby was put on continuous positive airway pressure (CPAP) as he developed respiratory distress syndrome (RDS) with which he had improvement in his respiratory status. On the seventh day he developed focal clonic seizures with secondary generalization. Computerized tomography (CT) brain revealed disseminated air collection in both the cerebral hemispheres [Figure 1] suggestive of cerebral air embolism (CAE). Review of other radiological investigations did not reveal any evidence of systemic air embolism. Repeat brain CT done two days later showed extensive bihemispherical infarcts [Figure 2]. He was given supportive care and discharged on stabilization. At 3 months follow-up the child had profound developmental delay and intractable epilepsy.

Cerebral air emboli are often micro-emboli, however massive CAE with survival have been documented..$^{[1,2]}$ CAE has been reported rarely in the neonates receiving positive pressure ventilation for RDS. ${ }^{[1,3]}$ Damaged pulmonary vascular integrity due to relatively higher pulmonary inflation pressure in RDS is supposed to facilitate the entry of air into systemic circulation, including the cerebral circulation. ${ }^{[1,3]}$ Recent studies suggest that prenatal exposure of the fetus to alcohol may have deleterious effect on the development of cerebral vasculature. ${ }^{[4]}$ This baby had been exposed to alcohol during prenatal period. Whether such exposure had any possible role in the development of massive CAE in this baby is speculative. This theory is tempting and only neuropathological studies in FAS may through a light.

Address for correspondence: Prof. San-Nan Yang, Division of Neonatology, Department of Pediatrics and Graduate Institute of Medicine,

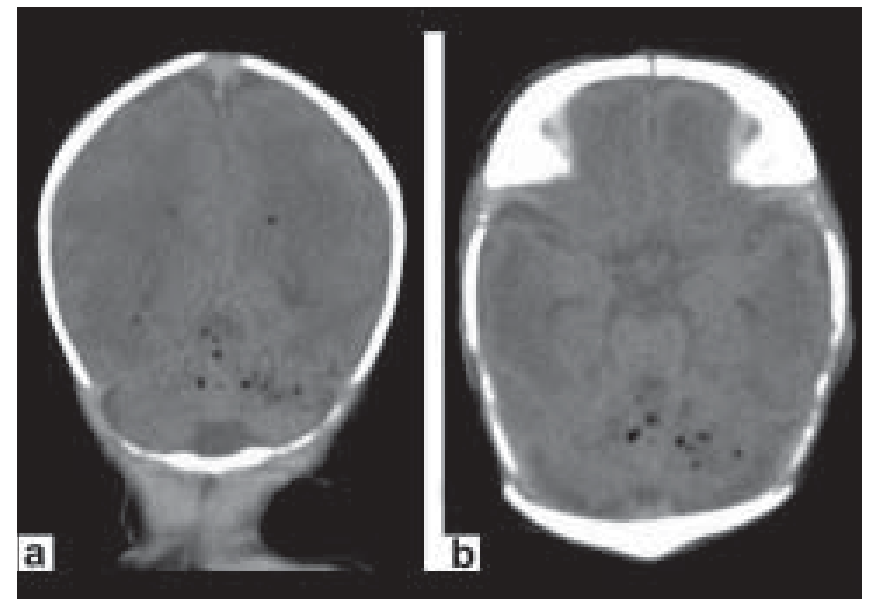

Figure 1(a, b): Coronal and axial sections of brain CT without contrast displayed multiple air bubbles within bilateral parieto-occipital lobes

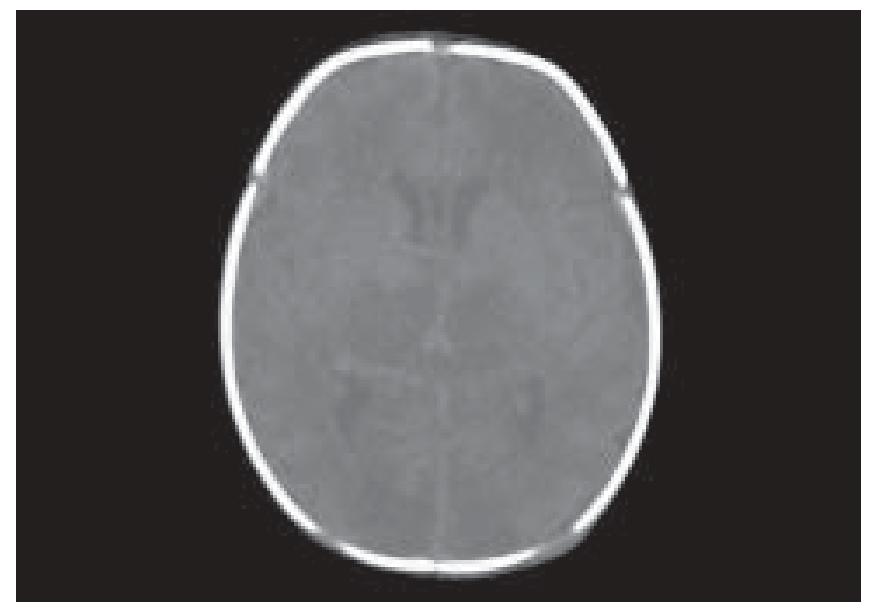

Figure 2: Diffused low attenuated areas in the bilateral thalami, temporal, occipital and parietal lobes appeared on repeat CT two days later

Kaohsiung M edical University, Kaohsiung, Taiwan 807. E-mail: y520729@ gmail.com 


\section{References}

1. Oppermann HC, Wille L, Obladen M, Richter E. Systemic air embolism in the respiratory distress syndrome of the newborn. Pediatr Radiol 1979;8:139-45.

2. Yang CW, Yang BP. Massive cerebral arterial air embolism following arterial catheterization. Neuroradiology 2005;47:892-4.
3. Fenton TR, Bennett S, McIntosh N. Air embolism in ventilated very low birth weight infants. Arch Dis Child 1988;63:541-3.

4. Solonskii AV, Logvinov SV, Kutepova NA. Development of brain vessels in human embryos and fetuses in conditions of prenatal exposure to alcohol. Neurosci Behav Physiol 2008;38:373-6.

Accepted on 06-03-2009

Source of Support: Nil, Conflict of Interest: None declared. 